\title{
From parasite encounter to infection: multiple-scale drivers of parasite richness in a wild social primate population
}

\begin{tabular}{|r|l|}
\hline Journal: & American Journal of Physical Anthropology \\
\hline Manuscript ID: & AJPA-2011-00098.R1 \\
\hline Wiley - Manuscript type: & Research Article \\
\hline Author: & n/a \\
\hline Complete List of Authors: & $\begin{array}{l}\text { Benavides, Julio; CNRS-Institut des Sciences de I'Evolution, } \\
\text { Université Montpellier II; Institute of Zoology, Zoological Society of } \\
\text { London } \\
\text { Huchard, Elise; German Primate Center, Department of Behavioral } \\
\text { Ecology and Sociobiology; Georg-August-University, Courant } \\
\text { Research Centre } \\
\text { Pettorelli, Nathalie; Institute of Zoology, Zoological Society of } \\
\text { London } \\
\text { King, Andrew; Royal Veterinary College, University of London, } \\
\text { Structure and Motion Laboratory; Institute of Zoology, Zoological } \\
\text { Society of London } \\
\text { Brown, Molly; NASA-Goddard Space Flight Center, SSAI } \\
\text { Archer, Colleen; University of KwaZulu-Natal, School of Biological } \\
\text { and Conservation Sciences } \\
\text { Appleton, Chris; University of KwaZulu-Natal, School of Biological } \\
\text { and Conservation Sciences } \\
\text { Raymond, Michel; CNRS-Institut des Sciences de l'Evolution, } \\
\text { Université Montpellier II } \\
\text { Cowlishaw, Guy; Institute of Zoology, Zoological Society of London }\end{array}$ \\
\hline Key Words: & \begin{tabular}{l} 
homerange use, gut parasites, physical condition, baboon, sociality \\
\hline \hline
\end{tabular} \\
\hline \hline
\end{tabular}


1 Title: From parasite encounter to infection: multiple-scale drivers of parasite richness

\section{2 in a wild social primate population}

3

4 Authors: Benavides JA ${ }^{\mathrm{a}, \mathrm{b},{ }^{*}}$, Huchard $\mathrm{E}^{\mathrm{c}, \mathrm{d}^{*}}$, Pettorelli $\mathrm{N}^{\mathrm{b}}$, King AJ ${ }^{\mathrm{b}, \mathrm{e}}$, Brown ME ${ }^{\mathrm{f}}$, Archer

$5 \quad \mathrm{CE}^{\mathrm{g}}$, Appleton $\mathrm{CC}^{\mathrm{g}}$, Raymond $\mathrm{M}^{\mathrm{a}}$, Cowlishaw $\mathrm{G}^{\mathrm{b}}$

6 Affiliations:

$7 \quad{ }^{a}$ CNRS - Institut des Sciences de l'Evolution, Université Montpellier II, Place Eugène

8 Bataillon, CC 065, 34095 Montpellier cedex 5, France

$9{ }^{\mathrm{b}}$ Institute of Zoology, Zoological Society of London, Regent's Park, London NW1 4RY, UK.

$10{ }^{\mathrm{c}}$ Department of Behavioral Ecology and Sociobiology, German Primate Center, Kellnerweg 11 4, 37077 Göttingen, Germany

$12{ }^{\mathrm{d}}$ Courant Research Centre "Evolution of Social Behavior", Georg-August-University,

13 Göttingen, Germany

$14{ }^{\mathrm{e}}$ Structure and Motion Laboratory, Royal Veterinary College, University of London,

15 Hawkshead Lane, North Mymms, Hatfield, Hertfordshire, AL9 7DY.

16 SSSA, NASA-Goddard Space Flight Center. Code 614.4, Greenbelt, MD 20771, USA

$17{ }^{\mathrm{g}}$ School of Biological and Conservation Sciences, University of KwaZulu-Natal, Durban, 18 South Africa.

19 *These two authors contributed equally.

21 Corresponding author: Julio Benavides

22 CNRS - Institut des Sciences de l'Evolution, Université Montpellier II, Place Eugène

23 Bataillon, CC 065, 34095 Montpellier cedex 5, France

24 Telephone number : + 33(0)4 67144966 / Fax number: + 33(0)4 67143622

25 Email: benavidesjulio@yahoo.fr

John Wiley 1 \& Sons, Inc. 
27 Number of text pages: 28

28 Number of references: 85

29 Number of graphs: 4

$30 \quad$ Number of tables: 5

31 Abbreviated title: Determinants of parasite richness in baboons

32 Key words: homerange use, gut parasites, physical condition, baboon, sociality.

\section{Grant sponsorship:}

34 This work was funded by a Natural Environment Research Council (NERC) (UK)

35 Project Grant and Advanced Fellowship awarded to GC, a NERC Studentship awarded to

36 AJK, a Ministère de l'Education et de la Recherche (France) Studentship awarded to EH and 37 JB, a Deutsches Forschungsgemeinschaft Research Grant (number HU 1820/1-1) awarded to $38 \mathrm{EH}$, and a CONICYT scholarship from the Chilean Government awarded to JB. 


\section{Abstract}

40

41 Host parasite diversity plays a fundamental role in ecological and evolutionary processes, yet 42 the factors that drive it are still poorly understood. A variety of processes, operating across a 43 range of spatial scales, are likely to influence both the probability of parasite encounter and 44 subsequent infection. Here, we explored eight possible determinants of parasite richness, 45 comprising rainfall and temperature at the population level, ranging behavior and home range productivity at the group level, and age, sex, body condition, and social rank at the individual level. We used a unique dataset describing gastrointestinal parasites in a terrestrial subtropical individuals representing all age-sex classes across two groups over two dry seasons in a desert 51 three spatial scales (population, group, individual); these were then standardised and combined in a single, global, mixed model. Individual age had the strongest influence on parasite richness, in a convex relationship. Parasite richness was also higher in females and 54 animals in poor condition, albeit at a lower order of magnitude than age. Finally, with a 55 further halving of effect size, parasite richness was positively correlated to day range and 56 temperature. These findings indicate that a range of factors influence host parasite richness 57 through both encounter and infection probabilities, but that individual-level processes may be 58 more important than those at the group or population level. 
Understanding the forces driving the spread of infectious diseases in wild animal populations is becoming increasingly important. From a theoretical perspective, parasites and pathogens are thought to play a primary role in driving population dynamics and evolutionary processes (Anderson and May 1978; Tompkins 2001). In population dynamics, wildlife diseases can lead to rapid declines in threatened species (Smith et al. 2009) and pose a growing threat as a source of human zoonoses (Jones et al. 2008). In evolutionary processes, infectious diseases have long been proposed as a significant pressure in the shaping of mating and social systems (Freeland 1976), partly because frequent contact rates between mates and social partners might greatly facilitate the transmission of pathogens.

Since most animals are infected by several parasite species, and even individually benign infections can have a cumulative pathogenic impact (McCallum 1994; McCallum and Dobson 1995), an understanding of the factors that determine the number of parasites an individual carries (i.e. host parasite richness) may be crucial to elucidating patterns of host vulnerability and the wider impacts of parasitism on host ecology and evolution (Bordes and Morand 2009). Indeed, host parasite richness has been linked to a diverse range of micro- and macro-ecological and evolutionary processes, such as adult mortality rates (Simkova et al. 2006), the population-level maintenance of polymorphisms in immune genes such as the major histocompatibility complex (mammals: Goüy de Bellocq et al. 2008; Simkova et al. 2006), and species diversification (e.g. primates: Nunn et al. 2004). Parasite richness is also becoming an increasingly important metric for understanding the impacts of anthropogenic disturbance on threatened taxa (e.g. primates: Chapman et al. 2005b; Gillespie et al. 2005; Valdespino et al. 2010).

Despite its importance, we know surprisingly little about the determinants of host parasite richness. Indeed, theoretical progress in this area is constrained by the dearth of empirical research - and this is particularly true for field data - and a lack of information 
necessary for modeling (Tompkins et al. 2010). Within species, a variety of forces can potentially interact with host susceptibilities to shape parasite transmission across a range of ecological scales, from populations to individuals (Tompkins et al. 2010). At the population level, seasonal environmental factors, such as increasing rainfall and temperature, are expected to increase parasite richness (Nunn and Altizer 2006), along with intrinsic factors such as population size and density, number of groups (for social species), and degree of population fragmentation (Chapman et al. 2005b; Morand and Poulin 1998; Nunn and Altizer 2006). At the group level (in socially structured populations), the group size, area and productivity of the home range, and daily travel distance might all affect parasite richness (Nunn and Altizer 2006; Vitone et al. 2004) (but see also Bordes et al. 2009; Snaith et al. 2008). Finally, at the individual level, a wide range of traits might influence parasite richness including body mass, age, social rank, reproductive state, hormone levels, immune status, and genetic constitution (for reviews, see : Nunn and Altizer 2006; Tompkins et al. 2010). However, identifying independent, contemporaneous, effects of such myriad factors across spatial scales, and assessing their relative importance, remains a substantial challenge especially when the complexity of factors involved necessitates an integrative approach, using concurrent monitoring of individuals and their environment through a longitudinal, rather than cross-sectional, design (Tompkins et al. 2010).

\section{[Please insert Table 1 here]}

Here we investigate the relative importance of a range of factors that might influence host parasite richness. We structure our analysis to recognise the multiple spatial scales over which these factors operate (i.e. the population, group, and individual), and specify whether their mode of action is most likely to affect parasite richness through the probability of 
110 encounter with parasites or the susceptibility to infection following encounter (sensu Nunn \&

111 Altizer, 2006). Our analysis focuses on patterns of gastrointestinal parasite richness in a wild

112 social primate population of chacma baboons (Papio ursinus). While individually-based

113 parasite studies in wild primates are uncommon (Nunn and Altizer 2006), they are of

114 particular interest for at least three reasons. First, wild primates are perhaps the most serious

115 wild source of cross-species disease transmission to humans, with sometimes catastrophic

116 consequences for public health (e.g. ebola: Leroy et al. 2004). Second, primates are a taxon of

117 high conservation concern, with disease posing a serious threat in some populations

118 (Chapman et al. 2005a). Finally, studying a social species will contribute to our understanding

119 of the dynamics of parasite transmission in group-living organisms that may be especially

120 vulnerable to infectious diseases (Altizer et al. 2003).

121 In Table 1, we detail the eight hypotheses tested. At the population level, our 122 hypotheses predicted that parasite richness would increase with wet (H1) or hot (H2) 123 conditions. At the group level, we predicted that parasite richness would be higher in more 124 productive home ranges (H3), or in association with more extensive ranging behavior (H4). 125 At the individual level, we predicted that parasite richness would be influenced by age (H5), 126 sex (H6), physical condition (H7), and social rank (H8). Finally, we investigated the relative 127 magnitude of the effects of all those factors that influence parasite richness, across spatial 128 scales, in a single global model.

129

MATERIALS AND METHODS

Study system

Our study was carried out on wild chacma baboons on the edge of the Namib Desert, 134 in central Namibia, at Tsaobis Leopard Park $\left(22^{\circ} 23^{\prime} \mathrm{S} 15^{\circ} 45^{\prime} \mathrm{W}\right)$. Tsaobis is characterized by 
135 mountains and rocky foothills that descend to rolling gravel and alluvial plains. Vegetation is

136 sparse, comprising grasses and herbs, shrubs and dwarf trees, although patches of aquifer-

137 dependent woodland grow along the ephemeral Swakop River bordering Tsaobis to the north.

138 The landscape is arid and strongly seasonal: annual rainfall is low (mean \pm SD: $123 \pm 77 \mathrm{~mm}$,

$139 \mathrm{n}=68$ years) and falls only during the austral summer, primarily between December and April.

140 The altitudinal range is $683-1445 \mathrm{~m}$. Shade temperatures can approach zero on winter nights,

141 but exceed $40^{\circ} \mathrm{C}$ on summer days.

142 Data were collected during two field seasons (June to December 2005, May to October

143 2006) on two social groups. These comprised, in October 2006, 9 adult or subadult males, 16

144 adult females, and 32 juveniles for the larger group (Troop J) and 7 adult or subadult males, 9

145 females and 16 juveniles for the smaller group (Troop L). All subjects were fully habituated 146 and individually identifiable.

A total of 662 faecal samples were collected immediately after defecation from 86

150 individuals. The faeces were homogenized and a portion (mean \pm SEM: $0.73 \pm 4.10^{-3} \mathrm{~g}$ ) was 151 weighed and stored in $4 \mathrm{ml}$ of $10 \%$ buffered formalin solution immediately after collection, at 152 room temperature. A mean of 8.1 samples per individual ( $\mathrm{SD}=6.40$, median=7, range: 1-37), 153 and 53.4 samples per month $(\mathrm{SD}=27.8$, median=61, range: $17-104)$, were collected through 154 the study period. Faecal analysis was carried out using the modified formol-ether 155 sedimentation technique (Allen and Ridley 1970), using merthiolate-formalin as a stain. 156 Parasitic eggs, larvae, trophs, and cysts were recorded by species or morphotype, with 157 measurements made to the nearest $0.1 \mathrm{~mm}$ using an ocular micrometer fitted to a compound 158 microscope (further details on parasite indentification see Appleton et al. 1991; Appleton et 159 al. 1986) Due to difficulties in identifying rounded-up trophozoites or pre-cystic stages within 
160 small-sized amoebae, Entamoeba hartmanni, Endolimax nana, and Dientamoeba fragilis

161 were pooled together into a morphotype designated as "small amoebae" (Fiennes 1972).

162 Similarly, Entamoeba chattoni, Entamoeba histolytica, Entamoeba dispar and Iodamoeba

163 buetchlii were pooled as "medium amoebae". Host parasite richness was estimated for each

164 faecal sample by the number of different species/morphotypes recorded. We assumed that

165 when species/morphotypes were present we were able to detect them, but some false

166 negatives may have occurred if a species was harder to detect when its intensity of infection

167 or reproductive output were lower.

168

169

Population-level environmental conditions (H1-H2)

170

Rainfall was monitored on a daily basis. Similarly, maximal temperatures (Tmax) in

171 the shade were recorded on a daily basis and were available for 179 days (78 \% of the study

172 period). Tmax varied across the study period (maximal mean $\pm \mathrm{SD}=31.9 \pm 4.8$, range $=[20$ -

173 41]), with maximal values during summer (December) and minimal values in winter (July) in

174 both years. Minimal and maximal daily temperatures were strongly correlated (Pearson's 175 correlations: $\mathrm{rho}=0.71, \mathrm{n}=283, P<2.10^{-16}$ ), so only Tmax was used here.

176

177

178

179

180

181

182

183

184

\section{Group-level range productivity and ranging behavior $(\mathrm{H} 3-\mathrm{H} 4)$}

Group location waypoints were taken at half-hour intervals over at least 100 full-day follows for each group conducted between May and November, thus covering periods of both high and low plant productivity in the late austral summer and winter. Minimum convex polygons (Heupel et al. 2004), were constructed around these waypoints in ArcMap Version 9.3 using HawthsTools extension package (http://www.spatialecology.com/htools/) to provide a simple estimation of the home range boundaries over the study period. Within the home ranges, plant production was estimated using the Normalized Difference Vegetation Index 
185 (NDVI: Pettorelli et al. 2011): a satellite-based vegetation index based on the information

186 collected by the Satellite Pour l'Observation de la Terre-Vegetation (SPOT VGT). NDVI is

187 derived from the red to the near-infrared reflectance ratio $[\mathrm{NDVI}=(\mathrm{NIR}-\mathrm{RED}) /(\mathrm{NIR}+\mathrm{RED})]$,

188 where NIR and RED are the amounts of near-infrared and red light, respectively, reflected by

189 the vegetation and captured by the satellite sensor (Jensen 2006). We use a spatial resolution

190 of $1 \times 1 \mathrm{~km}$ available at 10 -day intervals in each troop's home range ( $\mathrm{J}$ and $\mathrm{L})$. The home range

191 boundaries were also used to determine the monthly home range size for each group (J:

192 mean $\pm \mathrm{SD}=12.3 \pm 6.5 \mathrm{~km}^{2}$, range $=[5-27], \mathrm{L}: 26.8 \pm 13.5 \mathrm{~km}^{2}$, [8-49]), while the waypoint

193 locations were also converted into paths to measure daily travel distance for 208 days (92\% of

194 the study period) $(\mathrm{J}$ : mean $\pm \mathrm{SD}=5.9 \pm 0.8$, range $=[5.2-8.0], \mathrm{L}: 5.9 \pm 1.5,[2.6-7.3])$. In the 195 analyses, we use the mean daily travel distance per month.

196

197

198

199

200

201

202

203

204

205

206

207

208

209

\section{Individual traits (H5-H8)}

We investigated the influence of age, sex, body condition, and dominance rank on parasite richness. Age and condition were determined through individual inspection during troop captures: in J troop, 42 individuals (of 52) were captured in July 2005 and 55 (of 57) in October 2006, in L troop 32 individuals (of 32) were captured in October 2006. Briefly, troops were captured using individual cages baited with corn cobs and set-up at dusk. The baboons were captured at dawn, anaesthetised using tiletamine-zolazepam, and all processed within a day to be released together the following morning when fully awake. Age was estimated through dentition: tooth eruption schedules for wild baboons were used to assign age up to the eruption of the molars, while age beyond this point was estimated on the basis of molar wear (Huchard et al. 2009a). Body size was estimated by crown-rump length, measured during capture. Physical condition was measured through morphometric data. Because there is no consensus on the best way to index condition (Green 2001; Lukaski 1987), we used 
210 three different measures: (1) body mass, (2) mean skinfold thickness (MST), averaged across 211 the triceps, abdominal, and subscapular regions, and (3) mid upper-arm fat (MUAF), a 212 combination of the triceps skinfold thickness and the mid upper-arm circumference:

$213 \quad M U A F=\frac{S C}{2}-\frac{\pi S^{2}}{4}$

214 where $\mathrm{S}=$ triceps skinfold thickness and $\mathrm{C}=$ upper-arm circumference (Gibson 2005). In 215 order to summarize these three measures into one general index, we conducted a principal 216 component analysis (PCA). This analysis included all data from all individuals across 2005 217 and 2006 for which the three indices were available (49 out of 51 individuals). The 218 contribution of each measure to the first component (estimated through PCA square cosinus) 219 was $0.71,0.75$ and 0.91 for MUAF, MST and body mass, respectively. The first principal 220 component of the PCA accounted for $81 \%$ of the total condition variation, and was then used 221 as the body condition variable in our analyses. The mean time difference between our 222 assessment of parasite richness (i.e. a given faecal sample) and the closest estimate of 223 age/condition (at capture) was $73.4 \pm 46.9$ days.

224 Sex was determined by visual inspection. To establish dominance ranks, agonistic and 225 approach/avoid interactions (following Smuts 1985) were collected using ad libitum and focal 226 observations across the study period (for details see: Huchard et al. 2009b). In order to control 227 for differences in troop size, an animal's absolute rank is divided by the total number of 228 individuals in the group - thus alpha animals have the smallest rank. Ranks were estimated 229 for sexually mature individuals (females reach sexual maturity around 4 years of age and 230 males around 5 years of age: e.g. Altmann and Alberts 2003).

231 In summary, the data available for each individual variable were as follows: 86 232 individuals (662 samples) for sex, 76 individuals (613 samples) for age, 73 individuals (456 233 samples) for body condition, and 44 individuals (298 samples) for dominance rank. 
236 To test the influence of socio-ecological factors on individual parasite richness, we ran five 237 sets of Linear Mixed Models (LMMs) with parasite richness as the response variable. 238 Although our response variable was discrete, we used LMMs rather than Generalized Linear 239 Mixed Models (GLMMs) due to the need to incorporate temporal autocorrelation in the 240 analysis (see below) which is so far only possible using LMMs fitted with a Gaussian 241 distriution (Pinheiro and Bates 2000). The residuals of all models were constant and normally 242 distributed as checked by Q-Q plots and Shapiro-Wilk normality tests $(P>0.05$ in all 243 models). However, we also ran our models using GLMMs with a Poisson distribution (but 244 without the autocorrelation term) and obtained the same results. All models tested include 245 "baboon identity" nested in "troop membership" as random effects, to account for the non246 independence of multiple data collected from the same individual within a troop. Because 247 estimations of parasite richness can increase (in a non-linear way) with faecal sample weight 248 (Walther et al. 1995), we also controlled in each model for a potential effect of sample weight 249 by introducing it as a fixed factor at the third polynomial degree. This degree was selected 250 using an information theoretic approach: briefly, for each of the five models presented below, 251 we initially compared the Akaike Information Criterion (AIC) scores of three alternative 252 models with faecal sample weight fitted at the first, second and third order, and found that the 253 latter consistently performed best (i.e. presented an AIC score at least two points lower than 254 the alternative models). This third order relationship was further confirmed graphically by an 255 asymptotic curve linking parasite richness to faecal sample weight. As a final statistical 256 control, we also included the year of sample collection as a fixed effect. However, this was 257 not found to be significant in any model examined and was therefore excluded in the final set 258 of analyses, for simplicity. 
The first set of analyses occurred in three successive stages, exploring the effects of 260 the different variables at each considered scale (population, group, individual). The first 261 model was designed to investigate the effect of a population-level factor on host parasite 262 richness, specifically the effects of the maximum daily temperature (Tmax) averaged over the 263 seven-day period during which the individual was sampled (Hypothesis H2; the effects of 264 rainfall, Hypothesis H1, were tested independently due to the limited number of rainfall 265 events: see below). We further explored if Tmax collected before the time of faecal collection 266 predicted parasite richness better than contemporary measures by using an additional subset 267 of lagged models for Tmax. These models included maximum daily temperature averaged 268 across the seven-day period occurring one, two, three, four or five weeks before the sampling 269 date, compared by AIC and the Tmax p-value. The model including Tmax averaged four 270 weeks before sampling performed best (see Supporting Information Table S1), and was 271 therefore used in further analyses (the global model).

272 The second model was designed to investigate the group-level effects of home range 273 productivity (H3) and ranging behavior (H4.a,b) on host parasite richness. Therefore, it 274 included home range NDVI, home range area, and daily travel distances as fixed effects. As 275 for Tmax, we also tested the NDVI measure lagged for 10, 20 and 30 days before sampling 276 (as NDVI data were available for 10 days intervals), but found that contemporary NDVI 277 performed best (see Supporting Information Table S2).

278 The third model was designed to investigate the first three of our four individual-level 279 effects, namely age (H5), sex (H6), and body condition (H7), on host parasite richness. These 280 variables were all included as fixed effects in the same model. Age was introduced at the third 281 polynomial degree to account for a potential non-linear effect, which was suggested by 282 graphical exploration of the raw data and by a model AIC score 2 points lower than the 283 alternative models (i.e. with first or second polynomial degrees). Crown-rump length was 
284 additionally introduced in the model, to control for body size when investigating condition 285 effects (Jakob et al. 1996). To investigate the effects of our fourth individual-level factor on 286 host parasite richness, namely social rank (H8), we ran the individual-level model again for 287 the subset of animals for whom social ranks were available ( $\mathrm{N}=44$ adults), adding social 288 rank as a fixed effect. We also included a sex*rank interaction term to account for profound 289 sex differences in the acquisition of rank in this species (stable and heritable ranks among 290 females; fluctuating ranks determined by fighting ability among males).

291 Following our analyses of the factors determining host parasite richness at each of the 292 three spatial scales, we ran a final model to integrate our findings and to explore the relative 293 importance of each of these factors across scales. This global model included all the variables 294 that were found to be significant in the single-scale models, and was run using the full sample 295 (juveniles and adults). In order to compare the effect sizes of each variable in this global 296 model, all variables were standardized to have a mean of zero and a standard deviation of one. 297 In each model, we controlled for the temporal dependence of observations (i.e. temporal 298 autocorrelation) by including a temporal correlation structure of the residuals. We compared 299 the AIC of models having an autoregressive structure of order 1 to 7 (i.e. 1 to 7 lags of 300 dependence between observations). In all the model sets described above, the final model 301 with order 5 obtained the lowest AIC and was therefore selected. This was implemented using 302 the correlation structure corARMA (Pinheiro and Bates 2000) in the nlme package of R 2.8.0 303 (R Development Core Team, 2003). The significance of fixed effects was evaluated using F304 tests according to the principle of marginality, testing each fixed effect coefficient when all 305 other fixed effects are present in the model. Statistical significance is reported for full models 306 (i.e. inferences were drawn with all predictors present) throughout (Mundry and Nunn 2009; 307 Whittingham et al. 2006). The significance of random effects was tested by performing 308 likelihood ratio tests (following a $\chi 2$ distribution) comparing two models differing only in the 
309 presence of this effect. In all models, the random effect "troop identity" did not significantly 310 affect individual parasite richness (Likelihood Ratio Test, $P>0.05$ ) whereas "baboon 311 identity" always had a significant effect (Likelihood Ratio Test, $P<0.001$ ).

\section{RESULTS}

A total of 11 species or morphotypes of intestinal parasites including five nematodes,

316 one acanthocephalan and nine protozoan, were found in the faeces of $P$. ursinus at Tsaobis 317 (Table 2). One type of nematode egg, that occurred in $6 \%$ of individuals, could not be 318 identified further (named Egg 1 hereafter). Based on species/morphotype, the median 319 individual parasite richness was 3.00 (range $=0-8$, mean $\pm \mathrm{SD}=3.2 \pm 1.3)$.

[Please insert Table 2 here]

322

\section{Population-level environmental determinants of parasite richness (H1-H2)}

Host parasite richness decreased across the dry season (Fig. 1). However, a peak was observed in November 2005 (median=4.0; mean $\pm \mathrm{SD}=3.8 \pm 1.3$ ), 10 days after the first and only rain recorded in the study period (16mm, 29/10/05). During November, average individual values of parasite richness were significantly higher than in October 2005 (median=3.0, mean $\pm \mathrm{SD}=2.9 \pm 1.1$, Mann-Whitney test: $\mathrm{W}=1345.5, \mathrm{n}=86$ individuals, $P=$ 0.002), supporting our hypothesis that parasite richness increases after rainfall (H1). This difference was driven by protozoans (analyses excluding protozoans: $\mathrm{W}=3435, \mathrm{n}=86, P=$ $0.25)$. 
The best temperature predictor was Tmax averaged across the fourth week preceding 333 the sampling date (Table 3, Table S1), suggesting a lagged response of parasite richness. 334 Thus, host parasite richness was higher following hot weather four weeks earlier (Fig. 2).

\section{Group-level ranging determinants of parasite richness (H3-H4)}

Host parasite richness increased when groups travelled further, as predicted by 338 hypothesis H4.b. In contrast, there was no effect of home range NDVI (H3, for either contemporary or lagged measures, Table S2) or home range area (H4.a) (Table 3).

\section{Individual-level trait determinants of parasite richness (H5-H8)}

343 included as a control variable for condition) influenced host parasite richness (Table 3). Host 344 parasite richness initially increases with age (supporting H5.a), but then peaks around sexual 345 maturity, following which it declines (supporting H5.b) (Fig. 3). The sex effect indicated that 346 parasite richness was higher in females than in males (contrary to H6), while the condition 347 effect suggested that animals in better condition exhibited lower parasite richness (in support 348 of H7.b) (Table 3, Fig. 4). Among adults only, we found no evidence that dominance rank 349 affected parasite richness (failing to support H8), while the effects of age and sex were no 350 longer significant $(P>0.05$ in each case). The age effect remained non-significant when age 351 was included at the first or second order (instead of the third) in this last model (after sexual 352 maturity, the relationship between age and parasite richness appears roughly linear, Fig. 3). 353 However, adults in better condition still exhibited lower parasite richness than those in poor 354 condition $(\mathrm{F}=4.43, P=0.03)$. 


\section{Integrated global model for multiple-scale effects on parasite richness}

the effect sizes indicates that age had by far the strongest influence on parasite richness (effect

size $=3.92 \pm 1.46$ ) followed by sample weight (effect size $=2.75 \pm 1.03$ ). Sex and body

condition (together with body size) had comparable effect sizes, which were almost an order 363 of magnitude smaller than the age effect (effect size mean \pm SD $=-0.47 \pm 0.19$ and $-0.43 \pm$ 3640.13 respectively). Finally, travel distance and lagged Tmax had the smallest effects (effect 365 size $=0.21 \pm 0.06$ and $0.22 \pm 1.07$ respectively)

367 [Please insert Table 4 here]

\section{DISCUSSION}

Identifying the determinants of multiple parasite infections in wild animals is crucial 372 for both fundamental and applied, conservation-based, reasons, since they may represent 373 important drivers of both evolutionary change and population dynamics. However, there are 374 surprisingly few studies of the drivers of parasite richness in wild populations (Tompkins et 375 al. 2010), and most of these have worked at a single spatial scale. In this study, we found that 376 gut parasite richness in a wild primate population increases with higher rainfall and maximum 377 daily temperature at the population level, and with longer daily travel distances at the group 378 level, as well as showing more complex covariation with age, sex, and body condition at the 379 individual level. These findings, and how they compare to previous studies on parasite 380 richness in wild populations, are summarised in Table 5. Finally, integrating our analyses 
381 across the three scales of population, group, and individual, suggests that host age is the 382 primary predictor of parasite richness.

[Please insert Table 5 here]

385

At the population level, we observed significant effects of rainfall and maximum daily 387 temperature on host parasite richness, indicating an important influence of climatic conditions on parasite encounter rates. The increase in water-borne protozoan parasites associated with rainfall represents a preliminary result since it is based on only a single rainfall event. Nevertheless, it provides circumstantial evidence that precipitation can increase parasite 391 richness on a short timescale (H1). Parasite richness also increased following a period of hot 392 weather but with a four-week lag (H2). The mechanisms linking temperature to gastro393 intestinal parasite prevalence have been extensively studied, with several species of helminths 394 requiring a minimum temperature for development (Boag 1985), having shorter generation 395 times at relatively high temperatures, and/or producing more intermediate stages in their life 396 cycle when temperature increases (Pietrock and Marcogliese 2003). Protozoan taxa are 397 similarly affected, commonly displaying higher reproductive rates at higher temperatures 398 (Rodriguez-Zaragoza 1994). The lagged response most likely reflects the cumulative time 399 required by the free-living stages of parasites to react to environmental variation and for the 400 host to be exposed to, and contaminated by, the growing populations of infectious parasitic 401 forms.

402 At the group level, we found that longer daily travel distances (H4.b) but not larger 403 home ranges (H4.a) were associated with higher host parasite richness. This supports the idea 404 that more intensive movement patterns within a relatively stable home range, rather than 405 variation in the home range area itself, are associated with increased parasite exposure and 
406 subsequent infection with parasites that accumulate in the environment and mature in the host 407 to produce ova (Nunn and Altizer 2006). The lack of association between home range NDVI 408 and parasite richness (H3) further suggests that group-level changes in parasite encounter 409 rates primarily result from the group's behavioral response to environmental variation rather 410 than fluctuations in the density of infectious parasite stages, i.e. the baboons encounter more 411 parasites because their groups are travelling further, not because there are more parasites to 412 encounter per unit distance travelled.

413 At the individual level, we found co-variation between parasite richness and age, sex 414 and body condition. Previous research on the age-parasite richness relationship (H5) has 415 produced inconsistent results when assuming a linear pattern (Table 5). Our finding of a non416 linear relationship, positive before sexual maturity but negative afterwards, might help to 417 explain these inconsistencies - and reflect a combined effect of both encounter and infection 418 probabilities. In the first case, the positive part of the curve might reflect cumulative exposure 419 to parasites if the probability of encountering new parasite species is constant over time 420 (Nunn and Altizer 2006). This would suggest a relatively slow rate of acquisition of new 421 infections by young animals in this population. In the second case, the negative part of the 422 curve, exhibiting a weaker slope, might reflect an improved adaptive immune response 423 following repeated exposures to parasites (Hudson and Dobson 1997) and/or better 424 survivorship of those individuals possessing stronger immune defenses against multiple 425 infections. This hypothesis is supported by a recent study in this same population, where 426 MHC heterozygotes (class II Mhc-DRB region) appeared to show higher survivorship 427 (Huchard et al. 2010). Heterozygosity at MHC class II loci has already been found to mediate 428 individual parasite richness in natural populations (Goüy de Bellocq et al. 2008; Oliver et al. 429 2009). Multiple infections might thus constitute the selective pressure increasing the mortality 430 rate of individuals with low MHC diversity, if they display limited ability to fight multiple 
431 parasites, as previously found in fish hosts (Simkova et al. 2006). Notably, a recent 432 comparative primate study found that parasitic nematode richness associated positively with 433 the nonsynonymous nucleotide substitution rate at the functional part of the MHC molecule, 434 but not with MHC allelic diversity (Garamszegi and Nunn 2011). It is also possible that the 435 weaker relationship linking age to parasite richness after sexual maturity might at least 436 partially reflect the stabilization of individual parasite communities when they have reached a 437 given threshold, mediated through competitive interactions among multiple co-infecting 438 parasites (decreasing the probability of subsequent infection by additional parasite species) 439 (Graham 2008).

440 We also found that females harbour more parasite species than males (H6). Although 441 males are generally found to be more susceptible to parasitism than females (e.g. Klein 2004), 442 results from primate field studies have been less consistent, with several reported cases of 443 female-biased parasitism (e.g. Clough et al. 2010; reviewed in Nunn and Altizer 2006). In this 444 case, there is no reason to expect female baboons to have a higher probability of encounter 445 with parasites than males, so the most likely explanation for this difference is that females 446 have a higher susceptibility to infection. One possibility is a social effect, given that all adult 447 males outrank all adult females, but the lack of a sex*rank interaction does not support this. 448 Alternative explanations may relate to the costs of reproduction in females, including the 449 production of exaggerated sexual swellings when cycling and the nutritional stress associated 450 with pregnancy and lactation, or to complex interactions between sex hormones and immune 451 status. A recent field study in lemurs reported immune-enhancing effects of testosterone on 452 parasite species richness, suggesting that differences in immune responses due to sex steroids 453 might potentially lead to female-biased parasitism, at least in the case of host parasite richness 454 (Clough et al. 2010). 
Parasite richness was higher in poor-condition animals (H7.b) but there was no 456 evidence that dominant animals carried more or fewer parasite taxa (H8). Our findings for the 457 effects of physical condition corroborate the results of the one previous study to date that has 458 also explored this relationship (Lello et al. 2005). The negative association between body 459 condition and parasite richness suggests a role of infection rather than encounter probability, 460 but the direction of the causal arrow remains uncertain: while poor condition might reflect a 461 host's weak capacity to fight parasites on the one hand, it's also possible that the deleterious 462 effects of multiple infections could lead to poor condition on the other. In the latter case, 463 although most of the parasites reported here are not thought to be highly pathogenic, some 464 might still impact baboon health (Ruch 1959). The amoeba E. histolytica can cause severe 465 diarrheal and dysenteric diseases, and affect the liver, lungs, brain, and other areas; while 466 others like $B$. coli can become pathogenic if the host's natural resistance is depleted by a poor 467 diet (Ruch 1959). Whatever the causal direction, the observed association may help to explain 468 why females in better condition in this population display a higher reproductive success 469 (Huchard et al. 2009b). Our lack of rank effect was in contrast to theoretical expectations but 470 consistent with most previous empirical studies in primates (Table 5), and may reflect 471 confounding co-variation between rank and condition.

472 When focusing solely on adults, body condition remained the only individual trait 473 influencing parasite richness. In comparison with the full model including juveniles, the 474 disappearance of both age and sex effects reflects either decreased statistical power arising 475 from a smaller sample, or a weaker influence of such traits after sexual maturity. The latter 476 hypothesis is plausible in the case of age, since the slope of the relationship linking age to 477 parasite richness weakens in adulthood (Fig. 3), but seems counter-intuitive in the effect of 478 sex, which is usually reinforced among sexually mature individuals. Given that sex ratios are 479 relatively balanced in both our full and restricted sample, the disappearance of this effect 
480 among adults might reflect a genuine pattern. Post-hoc interpretation is necessarily 481 speculative, but could involve parental investment or maternal effects preferentially biased 482 towards male offspring, which might translate into improved parasite resistance in early life 483 (Hayward et al. 2010) - although the hypothesis of sex-biased maternal investment has not 484 been strongly supported by empirical studies of non-human primates so far (Bercovitch 2002; 485 Brown 2001).

The final global model integrating variables across scales largely confirmed the results 487 obtained within scales (all variables previously found to be significant in their respective single-scale models remained significant in the multi-scale model), but also emphasized the 489 importance of working at multiple ecological scales. Comparing the effect sizes of each variable in the global model suggests that the individual-level factors have a higher influence 491 on patterns of variation in parasite richness than population- or group-level factors. In fact, 492 age had by far the biggest effect on parasite richness, followed by sex and body condition, and 493 finally by maximal daily temperature and daily travel distance. As such, the global model 494 suggests that, while variation in encounter probability at both the population and group level 495 do influence host parasite richness, the strongest effects are related to both encounter and 496 infection probabilities at the individual level. Two areas of uncertainty in this interpretation 497 should be highlighted. First, due to the difficulties involved in working at wider spatial scales 498 with large social vertebrates, our sample of groups and populations is necessarily small. 499 Similarly, we only sample one season (the dry winter season) over two years, and it is 500 possible that in other seasons and/or years different patterns would be obtained. Extrapolation 501 of our conclusion (that individual-level processes play the predominant role) beyond the 502 sample and conditions investigated here should therefore be made with caution. Second, 503 estimation of the relative importance of encounter and infection probabilities at the individual 504 level is challenging. On the one hand, the effects of body condition (and probably sex) 
505 emphasize the importance of susceptibility to infection at the individual level. On the other,

506 the age effect includes both encounter and susceptibility to infection, with the former having

507 the strongest effect (since the negative relationship between age and parasite richness after

508 maturity is relatively weak). While neither of these uncertainties can be fully resolved here,

509 they do help to highlight those areas that might be prioritized for further research.

510 In conclusion, these findings demonstrate that host parasite richness in animal 511 populations may be associated with a range of factors operating on multiple scales. In this

512 case, parasite richness is highest in poor-condition females at the time of sexual maturity,

513 when their social group is travelling longer daily distances, and when environmental

514 conditions are characterized by high rainfall and temperature. This study also suggests that

515 individual traits, acting through both encounter and infection rates, can have a higher impact

516 on parasite richness than group- or population-level factors acting through encounter rates

517 alone. Our results emphasise the value of integrative approaches based on the longitudinal

518 sampling of known animals in well-documented ecological contexts, and suggests that such a

519 design can provide unique insights into the relative importance of different factors shaping

520 host parasite richness and its impact in wild populations.

\section{Acknowledgements}

We would like to thank N. Camara, H. Kelstrup, L. De Raad, R. Fleming, J. Kamps,

524 H. Marshall and H. Peck for their assistance in the field, and Celia Anderson for her help with 525 the parasite sample analysis. We are also grateful to the anonymous reviewers for their 526 thoughtful comments. We thank the Swart family (2000-2006) and the Ministry of Lands and 527 Resettlement (2006-07) for permission to work at Tsaobis Leopard Park, the Gobabeb 528 Training and Research Centre for affiliation, and the Ministry of Environment and Tourism 529 for research permission in Namibia. Our capture and processing protocols were assessed and 
530 approved by the Ethics Committee of the Zoological Society of London. We also confirm that 531 we adhered to the Guidelines for the Use of Animals in Behavioral Research and Teaching 532 (Animal Behaviour 2003, 65:249-255) and the legal requirements of the country (Namibia) in 533 which the work was carried out. This paper is a publication of the ZSL Institute of Zoology's 534 Tsaobis Baboon Project. Contribution ISEM 2011-088. 
Allen AVH, and Ridley DS. 1970. Further observations on formol-ether concentration technique for faecal parasites. Journal of Clinical Pathology 23(6):545-546.

Altizer S, Nunn CL, Thrall PH, Gittleman JL, Antonovics J, Cunningham AA, Dobson AP, Ezenwa V, Jones KE, Pedersen AB et al. . 2003. Social organization and parasite risk in mammals: Integrating theory and empirical studies. Annual Review of Ecology Evolution and Systematics 34:517-547.

Altmann J, and Alberts SC. 2003. Intraspecific variability in fertility and offpsring survival in a non-human primate: behavioral control of ecological and social sources. In: W WK, and A BR, editors. Offspring: human fertility behavior in a biodemographic perspective Washington, D.C: National Academy Press. p 140-169.

Anderson RM, and May RM. 1978. Regulation and stability of host-parasite population interactions . Regulatory processes. Journal of Animal Ecology 47(1):219-247.

Appleton CC, Henzi SP, and Whitehead SI. 1991. Gastrointestinal helminth-parasites of the chacma baboon, Papio cynocephalus ursinus, from the coastal lowlands of Zululand, South-Africa. African Journal of Ecology 29(2):149-156.

Appleton CC, Henzi SP, Whiten A, and Byrne R. 1986. The gastrointestinal parasites of Papio ursinus from the Drakensberg mountains, Republic of South-Africa. International Journal of Primatology 7(5):449-456.

Barbosa AM, Segovia JM, Vargas JM, Torres J, Real R, and Miquel J. 2005. Predictors of red Fox (Vulpes vulpes) helminth parasite diversity in the provinces of Spain.

Bavia ME, Malone JB, Hale L, Dantas A, Marroni L, and Reis R. 2001. Use of thermal and vegetation index data from earth observing satellites to evaluate the risk of schistosomiasis in Bahia, Brazil. Acta Tropica 79(1):79-85.

Bell G, and Burt A. 1991. The comparative biology of parasite species-diversity - internal helminths of fresh-water fish. Journal of Animal Ecology 60(3):1047-1063.

Bercovitch FB. 2002. Sex-biased parental investment in primates. International Journal of Primatology 23(4):905-921.

Boag B. 1985. Effect of temperature on the times to hatching of eggs of the plant-parasitic nematode Longidorus elongatus. Nematologia Mediterranea 13:61-66.

Bordes F, and Morand S. 2009. Parasite diversity: an overlooked metric of parasite pressures? Oikos 118(6):801-806.

Bordes F, Morand S, Kelt D, and Van Vuren DH. 2009. Home range and parasite diversity in mammals. The American Naturalist 173(4):467-474.

Brown GR. 2001. Sex-biased investment in nonhuman primates: can Trivers \& Willard's theory be tested. Animal Behaviour 61:683-694.

Calvete C. 2003. Correlates of helminth community in the red-legged partridge (Alectoris rufa L.) in Spain. Journal of Parasitology 89(3):445-451.

Ceccato P, Connor SJ, Jeanne I, and Thomson MC. 2005. Application of geographical information systems and remote sensing technologies for assessing and monitoring malaria risk. Parassitologia 47(1):81-96.

Chapman CA, Gillespie TR, and Goldberg TL. 2005a. Primates and the ecology of their infectious diseases: How will anthropogenic change affect host-parasite interactions? Evolutionary Anthropology 14(4):134-144.

Chapman CA, Gillespie TR, and Speirs ML. 2005b. Parasite prevalence and richness in sympatric colobines: Effects of host density. American Journal of Primatology 67(2):259-266.

Clayton DH, Gregory RD, and Price RD. 1992. Comparative ecology of neotropical bird lice (Insecta, Phthiraptera). Journal of Animal Ecology 61(3):781-795. 
584 Clough D, Heistermann M, and Kappeler PM. 2010. Host intrinsic determinants and potential

585

586

587

588

589

590

591

592

593

594

595

596

597

598

599

600

601

602

603

604

605

606

607

608

609

610

611

612

613

614

615

616

617

618

619

620

621

622

623

624

625

626

627

628

629

630

631

632 consequences of parasite infection in free-ranging red-fronted lemurs (Eulemur fulvus rufus). American Journal of Physical Anthropology.

Fiennes RN. 1972. Pathology of simian primates. . Basel, New York: karger.

Freeland W. 1976. Pathogens and the evolution of primate sociality. Biotropica 8:12:24.

Garamszegi LZ, and Nunn CL. 2011. Parasite-mediated evolution of the functional part of the MHC in primates. Journal of Evolutionary Biology 24(1):184-195.

Gibson RS. 2005. Principles of nutritional assessment. Oxford Oxford University Press.

Gillespie TR, Chapman CA, and Greiner EC. 2005. Effects of logging on gastrointestinal parasite infections and infection risk in African primates. Journal of Applied Ecology 42(4):699-707.

Goüy de Bellocq J, Charbonnel N, and Morand S. 2008. Coevolutionary relationship between helminth diversity and MHC class II polymorphism in rodents. Journal of Evolutionary Biology 21(4):1144-1150.

Graham AL. 2008. Ecological rules governing helminth-microparasite coinfection. Proceedings of the National Academy of Sciences of the United States of America 105(2):566-570.

Green AJ. 2001. Mass/length residuals: Measures of body condition or generators of spurious results? Ecology 82(5):1473-1483.

Guernier V, Hochberg ME, and Guegan JFO. 2004. Ecology drives the worldwide distribution of human diseases. Plos Biology 2(6):740-746.

Hayward AD, Pilkington JG, Pemberton JM, and Kruuk LEB. 2010. Maternal effects and early-life performance are associated with parasite resistance across life in free-living Soay sheep. Parasitology 137(8):1261-1273.

Heupel MR, Simpfendorfer CA, and Hueter RE. 2004. Estimation of shark home ranges using passive monitoring techniques. Environmental Biology of Fishes 71(2):135-142.

Huchard E, Benavides JA, Setchell JM, Charpentier MJE, Alvergne A, King AJ, Knapp LA, Cowlishaw G, and Raymond M. 2009a. Studying shape in sexual signals: the case of primate sexual swellings. Behavioral Ecology and Sociobiology 63(8):1231-1242.

Huchard E, Courtiol A, Benavides JA, Knapp LA, Raymond M, and Cowlishaw G. 2009b. Can fertility signals lead to quality signals? Insights from the evolution of primate sexual swellings. Proceedings of the Royal Society B-Biological Sciences 276(1663):1889-1897.

Huchard E, Knapp LA, Wang J, Raymond M, and Cowlishaw G. 2010. MHC, mate choice and heterozygote advantage in a wild social primate. Molecular Ecology in press.

Hudson PJ, and Dobson AP. 1997. Host-parasite processes and demographic consequences. In: Clayton DH, and Moore J, editors. Host-parasite evolution: general principles and avian models. Oxford: Oxford University Press. p 128-154.

Irvine RJ, Corbishley H, Pilkington JG, and Albon SD. 2006. Low-level parasitic worm burdens may reduce body condition in free-ranging red deer (Cervus elaphus). Parasitology 133:465-475.

Jakob EM, Marshall SD, and Uetz GW. 1996. Estimating fitness: A comparison of body condition indices. Oikos 77(1):61-67.

Jensen JR. 2006. Remote sensing of the environment:An earth resource perspective: Prentice Hall.

Jones KE, Patel NG, Levy MA, Storeygard A, Balk D, Gittleman JL, and Daszak P. 2008. Global trends in emerging infectious diseases. Nature 451(7181):990-994.

Klein SL. 2004. Hormonal and immunological mechanisms mediating sex differences in parasite infection. Parasite Immunology 26(6-7):247-264. 
633 Krasnov BR, Korallo-Vinarskaya NP, Vinarski MV, Shenbrot GI, Mouillot D, and Poulin R.

634

635

636

637

638

639

640

641

642

643

644

645

646

647

648

649

650

651

652

653

654

655

656

657

658

659

660

661

662

663

664

665

666

667

668

669

670

671

672

673

674

675

676

677

678

679

680

681 2008. Searching for general patterns in parasite ecology: host identity versus environmental influence on gamasid mite assemblages in small mammals. Parasitology 135(2):229-242.

Krasnov BR, Morand S, Hawlena H, Khokhlova IS, and Shenbrot GI. 2005. Sex-biased parasitism, seasonality and sexual size dimorphism in desert rodents. Oecologia 146(2):209-217.

Lello J, Boag B, and Hudson PJ. 2005. The effect of single and concomitant pathogen infections on condition and fecundity of the wild rabbit (Oryctolagus cuniculus). International Journal for Parasitology 35(14):1509-1515.

Leroy EM, Rouquet P, Formenty P, Souquiere S, Kilbourne A, Froment JM, Bermejo M, Smit S, Karesh W, Swanepoel R et al. . 2004. Multiple Ebola virus transmission events and rapid decline of central African wildlife. Science 303(5656):387-390.

Lindenfors P, Nunn CL, Jones KE, Cunningham AA, Sechrest W, and Gittleman JL. 2007. Parasite species richness in carnivores: effects of host body mass, latitude, geographical range and population density. Global Ecology and Biogeography 16(4):496-509.

Lindsay SW, Wilkins HA, Zieler HA, Daly RJ, Petrarca V, and Byass P. 1991. Ability of Anopheles gambiae mosquitos to transmit malaria during the dry and wet seasons in an area of irrigated rice cultivation in the gambia. Journal of tropical medicine and hygiene 94(5):313-324.

Lo CM, Morand S, and Galzin R. 1998. Parasite diversity host age and size relationship in three coral-reef fishes from French Polynesia. International Journal for Parasitology 28(11):1695-1708.

Lukaski HC. 1987. Methods for the assessment of human-body composition - Traditional and new. American Journal of Clinical Nutrition 46(4):537-556.

McCallum H. 1994. Quantifying the effect of disease on threatened species. Pacific Conservation 1:107-117.

McCallum H, and Dobson A. 1995. Detecting disease and parasite threats to endangered species and ecosystems. Trends Ecol Evol 10(5):190-194.

Mohr CO, and Stumpf WA. 1964. Relation of tick and chigger infestations to home areas of california meadow mice. Journal of Medical Entomology 1:73-77.

Morand S, De Bellocq JG, Stanko M, and Miklisova D. 2004. Is sex-biased ectoparasitism related to sexual size dimorphism in small mammals of Central Europe? Parasitology 129:505-510.

Morand S, and Harvey PH. 2000. Mammalian metabolism, longevity and parasite species richness. Proceedings of the Royal Society of London Series B-Biological Sciences 267(1456):1999-2003.

Morand S, and Poulin R. 1998. Density, body mass and parasite species richness of terrestrial mammals. Evolutionary Ecology 12(6):717-727.

Muehlenbein MP. 2005. Parasitological analyses of the male chimpanzees (Pan troglodytes schweinfurthii) at Ngogo, Kibale National Park, Uganda. American Journal of Primatology 65(2):167-179.

Mundry R, and Nunn CL. 2009. Stepwise Model Fitting and Statistical Inference: Turning Noise into Signal Pollution. American Naturalist 173(1):119-123.

Nunn CL, and Altizer S. 2006. Infectious diseases in primates: behaviour, ecology and evolution. . Oxford: Oxford University Press.

Nunn CL, Altizer S, Jones K, and Sechrest W. 2003. Comparative tests of parasite species richness in primates. The American Naturalist 162(5):597-614. 
682 Nunn CL, Altizer S, Sechrest W, Jones KE, Barton RA, and Gittleman JL. 2004. Parasites and 683 the evolutionary diversification of primate clades. American Naturalist 164(5):S90684 685 686 687 688 689 690 691 692 693 694 695 696 697 698 699 700 701 702 703 704 705 706 707 708 709 710 711 712 713 714 715

Nunn CL, and Dokey ATW. 2006. Ranging patterns and parasitism in primates. Biology Letters 2(3):351-354.

Oliver MK, Telfer S, and Piertney SB. 2009. Major histocompatibility complex (MHC) heterozygote superiority to natural multi-parasite infections in the water vole (Arvicola terrestris). Proceedings of the Royal Society Biological Sciences Series B 276(1659):1119-1128.

Pettorelli N, Ryan S, Mueller T, Bunnefeld N, Jedrzejewska B, Lima M, and Kausrud K. 2011. The Normalized Difference Vegetation Index (NDVI): unforeseen successes in animal ecology. Climate Research Accepted.

Pietrock M, and Marcogliese DJ. 2003. Free-living endohelminth stages: at the mercy of environmental conditions. Trends in Parasitology 19(7):293-299.

Pinheiro JC, and Bates DM. 2000. Mixed-effects Models in S and S-plus. New York: Springer.

Ranta E. 1992. Gregariousness versus solitude - another look at parasite faunal richness in canadian fresh-water fishes. Oecologia 89(1):150-152.

Rich SM, Leendertz FH, Xu G, LeBreton M, Djoko CF, Aminake MN, Takang EE, Diffo JLD, Pike BL, Rosenthal BM et al. . 2009. The origin of malignant malaria. Proceedings of the National Academy of Sciences of the United States of America 106(35):14902-14907.

Roberts ML, Buchanan KL, and Evans MR. 2004. Testing the immunocompetence handicap hypothesis: a review of the evidence. Animal Behaviour 68:227-239.

Rodriguez-Zaragoza S. 1994. Ecology of free-living amebas. Critical Reviews in Microbiology 20(3):225-241.

Rohde K, and Heap M. 1998. Latitudinal differences in species and community richness and in community structure of metazoan endo- and ectoparasites of marine teleost fish. International Journal for Parasitology 28(3):461-474.

Ruch TC. 1959. Diseases of laboratory primates. Philadelphia: W.B. Saunders Company. 121-145 p.

Setchell JM, Bedjabaga IB, Goossens B, Reed P, Wickings EJ, and Knapp LA. 2007. Parasite prevalence, abundance, and diversity in a semi-free-ranging colony of Mandrillus sphinx. International Journal of Primatology 28(6):1345-1362.

Simkova A, Ottova E, and Morand S. 2006. MHC variability, life-traits and parasite diversity of European cyprinid fish. Evolutionary Ecology 20(5):465-477.

Smith KF, Acevedo-Whitehouse K, and Pedersen AB. 2009. The role of infectious diseases in biological conservation. Animal Conservation 12(1):1-12.

Smuts BB. 1985. Sex and friendship in baboons. Hawthorne, NY: Aldine Publishing Co.

Snaith TV, Chapman CA, Rothman JM, and Wasserman MD. 2008. Bigger Groups Have Fewer Parasites and Similar Cortisol Levels: A Multi-Group Analysis in Red Colobus Monkeys. American Journal of Primatology 70(11):1072-1080.

Teichroeb JA, Kutz SJ, Parkar U, Thompson RCA, and Sicotte P. 2009. Ecology of the gastrointestinal parasites of Colobus vellerosus at Boabeng-Fiema, Ghana: possible anthropozoonotic transmission. American Journal of Physical Anthropology 140(3):498-507.

Tompkins DM. 2001. Parasites and host population dynamics. In: Hudson PJ, and Dobson AP, editors. Ecology of wildlife diseases Oxford: Oxford UniversityPress. p 45-62.

Tompkins DM, Dunn AM, Smith MJ, and Telfer S. 2010. Wildlife diseases: from individuals to ecosystems. Journal of Animal Ecology in press. 
732 Vacher C, Vile D, Helion E, Piou D, and Desprez-Loustau ML. 2008. Distribution of parasitic

733

734

735

736

737

738

739

740

741

742

743

744

745

746

747

748

749

750

751

752

753 fungal species richness: influence of climate versus host species diversity. Diversity and Distributions 14(5):786-798.

Valdespino C, Rico-Hernandez G, and Mandujano S. 2010. Gastrointestinal Parasites of Howler Monkeys (Alouatta palliata) Inhabiting the Fragmented Landscape of the Santa Marta Mountain Range, Veracruz, Mexico. American Journal of Primatology 72(6):539-548.

Vitone ND, Altizer S, and Nunn CL. 2004. Body size, diet and sociality influence the species richness of parasitic worms in anthropoid primates. Evolutionary Ecology Research 6(2):183-199.

Walther BA, Cotgreave P, Price RD, Gregory RD, and Clayton DH. 1995. Sampling effort and parasite species richness. Parasitology Today 11(8):306-310.

Watve MG, and Sukumar R. 1995. Parasite abundance and diversity in Mammals - Correlates with host ecology. Proceedings of the National Academy of Sciences of the United States of America 92(19):8945-8949.

Whittingham MJ, Stephens PA, Bradbury RB, and Freckleton RP. 2006. Why do we still use stepwise modelling in ecology and behaviour? Journal of Animal Ecology 75(5):11821189.

Zuk M, and McKean KA. 1996. Sex differences in parasite infections: Patterns and processes. International Journal for Parasitology 26(10):1009-1023. 
1 Table 1. Potential factors influencing host parasite richness explored in this study. Factors are grouped by the scale at which they operate 2 (population, group, and individual). Further information is also provided on the proposed mechanism (whether each factor is more likely to 3 influence parasite richness through the probability of parasite encounter or susceptibility to infection following encounter). The positive effect of 4 a considered factor is noted (+), and a negative effect is noted (-).

5

\begin{tabular}{|c|c|c|c|}
\hline Scale & Factor & & Hypotheses under test \\
\hline \multirow[t]{2}{*}{ Population } & Rainfall & H1 & $\begin{array}{l}\text { (+) encounter probability } \sim \text { due to the accelerated development, replication or survival of parasites } \\
\text { in wetter conditions (Nunn and Altizer, 2006). }\end{array}$ \\
\hline & Temperature & $\mathrm{H} 2$ & $\begin{array}{l}(+) \text { encounter probability } \sim \text { due to the accelerated development, replication or survival of parasites } \\
\text { in hotter conditions (Nunn and Altizer, 2006). }\end{array}$ \\
\hline \multirow[t]{3}{*}{ Group } & $\begin{array}{l}\text { Home range } \\
\text { productivity }\end{array}$ & $\mathrm{H} 3$ & $\begin{array}{l}\text { (+) encounter probability because vegetation can be a surrogate measure of environmental } \\
\text { moisture and thermal conditions for parasites (Bavia et al., 2001) or can represent a breeding or } \\
\text { sheltering site for parasites (Ceccato et al., 2005; Lindsay et al., 1991) }\end{array}$ \\
\hline & \multirow{2}{*}{$\begin{array}{l}\text { Ranging } \\
\text { behavior }\end{array}$} & H4.a & $\begin{array}{l}\text { Home range size: } \\
(+) \text { encounter probability } \sim \text { due to an increased probability of encounters with parasites in a larger } \\
\text { home range (Nunn and Altizer, 2006). }\end{array}$ \\
\hline & & H4.b & $\begin{array}{l}\text { Daily travel distance: } \\
(+) \text { encounter probability due to an increased probability of encounters with parasites in a more } \\
\text { intensively used home range (Nunn and Altizer, 2006). }\end{array}$ \\
\hline \multirow[t]{2}{*}{ Individual } & \multirow{2}{*}{ Age } & H5.a & $\begin{array}{l}(+) \text { encounter probability } \sim \text { due to an accumulation of parasites in older individuals resulting from a } \\
\text { stable probability of encounters with new parasites over time (Nunn and Altizer, 2006) }\end{array}$ \\
\hline & & H5.b & $\begin{array}{l}\text { (-) susceptibility to infection } \sim \text { due to a reinforced immunity in older individuals following repeated } \\
\text { contacts with multiple parasites (Hudson and Dobson, 1997) }\end{array}$ \\
\hline
\end{tabular}




\begin{tabular}{|c|c|c|}
\hline \multirow{2}{*}{ Sex } & \multirow{2}{*}{ H6 } & $\begin{array}{l}\text { (+ males) encounter probability } \sim \text { higher parasite richness in males due to higher consumption of } \\
\text { food and thus more opportunity to eat contaminated items (Nunn and Altizer, 2006) }\end{array}$ \\
\hline & & $\begin{array}{l}\text { (+ males) susceptibility to infection } ~ \text { higher parasite richness in males (Zuk and McKean, 1996), } \\
\text { due to immunosuppression typically resulting from elevated testosterone levels (Roberts et al., } \\
\text { 2004) }\end{array}$ \\
\hline \multirow{2}{*}{$\begin{array}{l}\text { Physical } \\
\text { condition }\end{array}$} & H7.a & $\begin{array}{l}(+) \text { exposure probability } \sim \text { animals that eat more are in better physical condition but also have more } \\
\text { opportunity to eat contaminated items (Nunn and Altizer, 2006) }\end{array}$ \\
\hline & H7.b & $\begin{array}{l}\text { (-) susceptibility to infection } \sim \text { due to a better ability to resist infections for animals in good physical } \\
\text { condition (Irvine et al., 2006) }\end{array}$ \\
\hline \multirow{2}{*}{ Social rank ${ }^{1}$} & H8.a & $\begin{array}{l}\text { (+) encounter probability } \sim \text { higher parasite richness in dominant individuals due to higher } \\
\text { consumption of food and thus more opportunity to eat contaminated items (Nunn and Altizer, } \\
\text { 2006) }\end{array}$ \\
\hline & H8.b & $\begin{array}{l}\text { (-) susceptibility to infection } \sim \text { higher parasite richness in subordinate individuals due to stress } \\
\text { compromising immunocompetence (Nunn and Altizer, 2006) }\end{array}$ \\
\hline
\end{tabular}


Table 2. Individual patterns of parasite infection (662 samples, 86 individuals), with species/morphotypes ordered by prevalence. The "Medium Amoebae" category includes $E$. histolytica, E. dispar and I. buetchlii. The "Small Amoebae" category includes E. hartmanni, E. nana, and D. fragilis. "Egg 1" corresponds to an unidentified nematode species. For nematodes, the median and range of intensity of infection is expressed in egg per gram. For protozoans, the intensity of infection is expressed as a score on a 5-point semi-quantitative scale (0-4). Parasite prevalence is expressed as the number of individuals infected by a given parasite species (or category in the case of medium and small amoebae) divided by the total number of individuals, and is given in percentage.

\begin{tabular}{ccccc}
\hline Species & Median & Range & Prevalence (\%) & Parasite phylum \\
\hline Streptopharagus pigmentatus & 153.4 & $0.0-4431.5$ & 77.5 & Nematode \\
Entamoeba coli & 1.6 & $0.0-3.0$ & 77.1 & Amoeboid \\
Balantidium coli & 1.3 & $0.0-4.0$ & 66.6 & Ciliate \\
Small-sized amoebae & 0.4 & $0.0-3.0$ & 30.3 & Amoeboid \\
Chilomastix mesnili & 0.3 & $0.0-1.7$ & 23.1 & Flagellate \\
Medium-sized amoebae & 0.5 & $0.0-2.0$ & 21.9 & Amoeboid \\
Physaloptera caucasia & 0.0 & $0.0-464.5$ & 14.6 & Nematode \\
Unidentified species (Egg1) & 0.0 & $0.0-30.7$ & 5.8 & Nematode \\
Ascaris sp. & 0.0 & $0.0-81$ & 0.02 & Nematode \\
Subulura sp. & 0.0 & $0.0-98$ & 0.01 & Nematode \\
Macracanthorhynchus hirudinaceus & 0.0 & $0.0-1$ & 0.01 & Acanthocephalan \\
\hline
\end{tabular}


Table 3. Influence of environmental factors, ranging behavior, and individual traits on individual baboon parasite richness. Each model represents a different scale: population-level factors (524 samples, 82 individuals, AIC=1685.28), group-level factors (599 samples, 86 individuals, $\mathrm{AIC}=1955.47$ ) and individual-level factors (456 samples, 73 individuals, $\mathrm{AIC}=1437.07)$.

\begin{tabular}{|c|c|c|c|c|c|c|}
\hline Model & Variables & Estimate & SE & F-value & $\mathrm{df}$ & P-value \\
\hline \multirow[t]{2}{*}{ Population level } & Sample weight^3 & 2.06 & 1.17 & 3.16 & 3 & 0.03 \\
\hline & $\operatorname{Tmax}{ }^{1}$ & 4.83 & 1.73 & 7.75 & 1 & $<0.01$ \\
\hline \multirow[t]{4}{*}{ Group level } & Sample weight ${ }^{\wedge} 3$ & 2.20 & 1.19 & 3.02 & 3 & 0.03 \\
\hline & Home range NDVI & 3.31 & 4.28 & 0.6 & 1 & 0.44 \\
\hline & Home range area & -0.01 & 0.01 & 1.44 & 1 & 0.23 \\
\hline & Travel distance & 0.28 & 0.07 & 15.95 & 1 & $<0.001$ \\
\hline \multirow[t]{5}{*}{ Individual level } & Sample weight^3 & 3.30 & 1.06 & 4.32 & 3 & $<0.01$ \\
\hline & $\mathrm{Age}^{\wedge} 3$ & 3.45 & 1.58 & 2.85 & 3 & 0.03 \\
\hline & $\mathrm{Sex}^{2}$ & -0.53 & 0.19 & 7.5 & 1 & $<0.01$ \\
\hline & Body condition & -0.18 & -0.08 & 5.08 & 1 & 0.02 \\
\hline & Body size & 0.01 & 0.01 & 4.45 & 1 & 0.04 \\
\hline
\end{tabular}


Table 4. Multiple-scale influences on baboon parasite richness (386 samples, 72 individuals, AIC $=1170.02)$. All variables were standardised (mean of zero, standard deviation of one) and are ordered by their effect size.

\begin{tabular}{|c|c|c|c|c|c|}
\hline Variables & Estimate & SE & F-value & df & $P$-value \\
\hline $\mathrm{Age}^{\wedge} 3$ & 3.92 & 1.46 & 4.41 & 3 & $<0.01$ \\
\hline Sample weight ${ }^{\wedge} 3$ & 2.75 & 1.03 & 5.79 & 3 & $<0.001$ \\
\hline Body size & 0.48 & 0.19 & 6.24 & 1 & 0.01 \\
\hline $\operatorname{Sex}{ }^{1}$ & -0.47 & 0.19 & 5.97 & 1 & 0.02 \\
\hline Body condition & -0.43 & 0.13 & 11.22 & 1 & $<0.001$ \\
\hline Tmax (with four-week lag) ${ }^{2}$ & 0.22 & 1.07 & 5.79 & 1 & $<0.01$ \\
\hline Travel distance & 0.21 & 0.06 & 10.56 & 1 & 0.001 \\
\hline \multicolumn{6}{|c|}{${ }^{1}$ The reference category for sex is female. } \\
\hline
\end{tabular}


Table 5. Evidence from previous empirical studies. Previous studies in captivity, or studies examining other parasitic measures such as prevalence or load, are not reported here. The positive effect of a considered factor is noted (+), a negative effect is noted (-), and no effect is noted by (0).

\begin{tabular}{|c|c|c|c|}
\hline Scale & Factor & Evidence from previous empirical studies & This study \\
\hline \multirow[t]{2}{*}{ Population } & Rainfall & $\begin{array}{l}\text { (+) comparative studies: bacteria across human populations (Guernier et } \\
\text { al., 2004); gamasid mites across small mammals (Krasnov et al., } \\
\text { 2008) } \\
\text { (0) field study of helminths in red foxes (Barbosa et al., 2005) }\end{array}$ & $(+)$ \\
\hline & Temperature & $\begin{array}{l}\text { (+) comparative study of fungi in French forest (Vacher et al., 2008); } \\
\text { field study of helminthes in red-legged partridge (Calvete, 2003) } \\
\text { (0) comparative studies: all parasite types in humans at large } \\
\text { geographical scale (Guernier et al., 2004); endo- and ectoparasites in } \\
\text { fish (Rohde and Heap, 1998); field study of helminthes in red foxes } \\
\text { (Barbosa et al., 2005) }\end{array}$ & $(+)$ \\
\hline \multirow[t]{3}{*}{ Group } & $\begin{array}{l}\text { Home range } \\
\text { productivity }\end{array}$ & No previous studies & $\mathbf{0}$ \\
\hline & $\begin{array}{l}\text { Home range } \\
\text { size }\end{array}$ & $\begin{array}{l}\text { (0) comparative study of gut parasites in mammals (Watve and } \\
\text { Sukumar, 1995) } \\
\text { (-) comparative study of helminths in mammals (Bordes et al., 2009) }\end{array}$ & $\mathbf{0}$ \\
\hline & $\begin{array}{c}\text { Daily travel } \\
\text { distance }\end{array}$ & $\begin{array}{l}\text { (+) comparative study of helminths in primates (Nunn and Dokey, } \\
\text { 2006); field study of chigger infections in California meadow mice } \\
\text { (Mohr and Stumpf, 1964) }\end{array}$ & $(+)$ \\
\hline \multirow[t]{4}{*}{ Individual } & Age & $\begin{array}{l}\text { (+) Longevity: comparative studies of Protozoans across primates } \\
\text { (Nunn et al., 2003); ectoparasites across Pericidae fish (Ranta, 1992); } \\
\text { helminths across freshwater fish (Bell and Burt, 1991); field study of } \\
\text { endo- and ectoparasites in coral-reef fish (Lo et al., 1998) } \\
\text { (0) Longevity: comparative study of ectoparasites across cyprinid fish } \\
\text { (Simkova et al., 2006); field studies of gut parasites: red-fronted } \\
\text { lemurs (Clough et al., 2010); mandrills (Setchell et al., 2007); } \\
\text { chimpanzees (Muehlenbein, 2005) } \\
\text { (-) Longevity: comparative study of helminths across mammals } \\
\text { (Morand and Harvey, 2000) }\end{array}$ & $\begin{array}{l}\text { Polynomial } \\
\text { relationship } \\
\text { with (+) } \\
\text { effect before } \\
\text { sexual } \\
\text { maturity and } \\
\text { a (-) effect } \\
\text { for adults }\end{array}$ \\
\hline & Sex & $\begin{array}{l}\text { (+ males) comparative study: ectoparasites in small mammals (Morand } \\
\text { et al., 2004); field study of fleas in desert rodents (Krasnov et al., } \\
\text { 2005) } \\
\text { (+ females) field studies: fleas in rodent Acromys russatus (Krasnov et } \\
\text { al., 2005); lice in neotropical birds (Clayton et al., 1992) } \\
\text { (0) No bias: field study of gut parasites in red-fronted lemurs (Clough et } \\
\text { al., 2010) }\end{array}$ & (+ females) \\
\hline & $\begin{array}{l}\text { Physical } \\
\text { condition }\end{array}$ & (-) field study of helminths of the wild rabbit (Lello et al., 2005) & $(-)$ \\
\hline & Social rank ${ }^{1}$ & $\begin{array}{l}\text { (+) field study of gut parasites in chimpanzees (Muehlenbein, 2005) but } \\
\text { analyses not shown. } \\
\text { (0) field studies: gut parasites in ursine colobus (Teichroeb et al., 2009); } \\
\text { red-fronted lemurs (Clough et al., 2010); mandrills (Setchell et al., } \\
\text { 2007) }\end{array}$ & $\mathbf{0}$ \\
\hline
\end{tabular}


${ }^{1}$ Here assuming high social rank for dominant individuals, low social rank for subordinates 


\section{Figure legends}

Fig. 1. Temporal variation of parasite richness during the study period. Monthly variation in parasite richness for the 2005 and 2006 study periods (means and standard errors) are displayed in the top panel. Monthly parasite prevalence (expressed as a fraction of total individuals) for each parasite species or morphotype for the 2005 study period are displayed on the bottom panel.

Fig. 2. Relationship between host parasite richness and daily maximum temperature (Tmax), averaged over the seven-days occurring four weeks before sample collection. The means and standard errors of Tmax for each parasite richness score are shown.

Fig. 3. Relationship between host parasite richness and age. Circles represent the mean parasite richness for an individual. The fitted line was drawn using a locally weighted polynomial regression (Cleveland, 1979) with the lowess command in $\mathrm{R} 2.8 .0$ ( $\mathrm{R}$ Development Core Team, 2003).

Fig. 4. Relationship between host parasite richness and physical condition. The means and standard errors of physical condition for each parasite richness score are shown. 

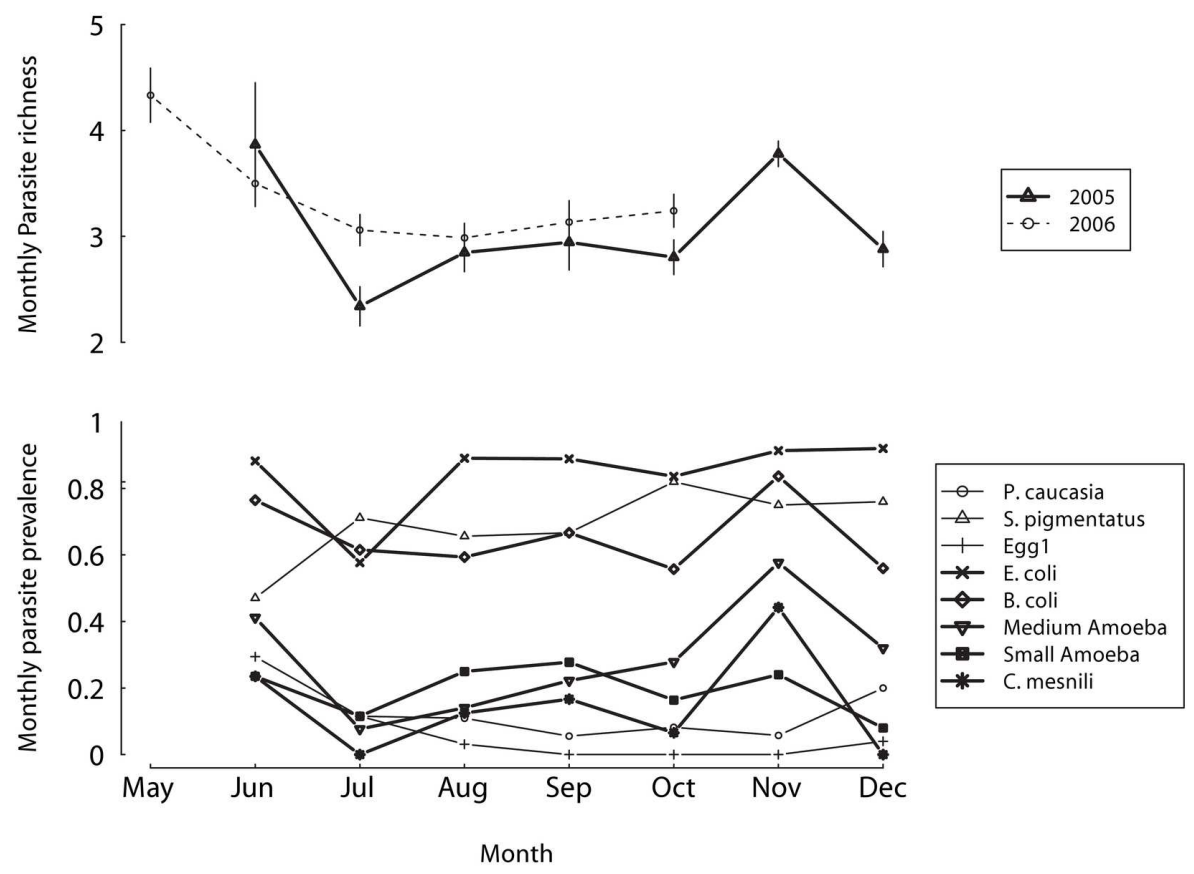

Fig1

$153 \times 112 \mathrm{~mm}(300 \times 300$ DPI $)$

John Wiley \& Sons, Inc. 


1
1
3
4
5
6
7
8
9
10
11
12
13
14
15
16
17
18
19
20
21
22
23
24
25
26
27
28
29
30
31
32
33
34
35
36
37
38
39
40
41
42
43
44
55
50
56
57
48
59
50
51
53
50

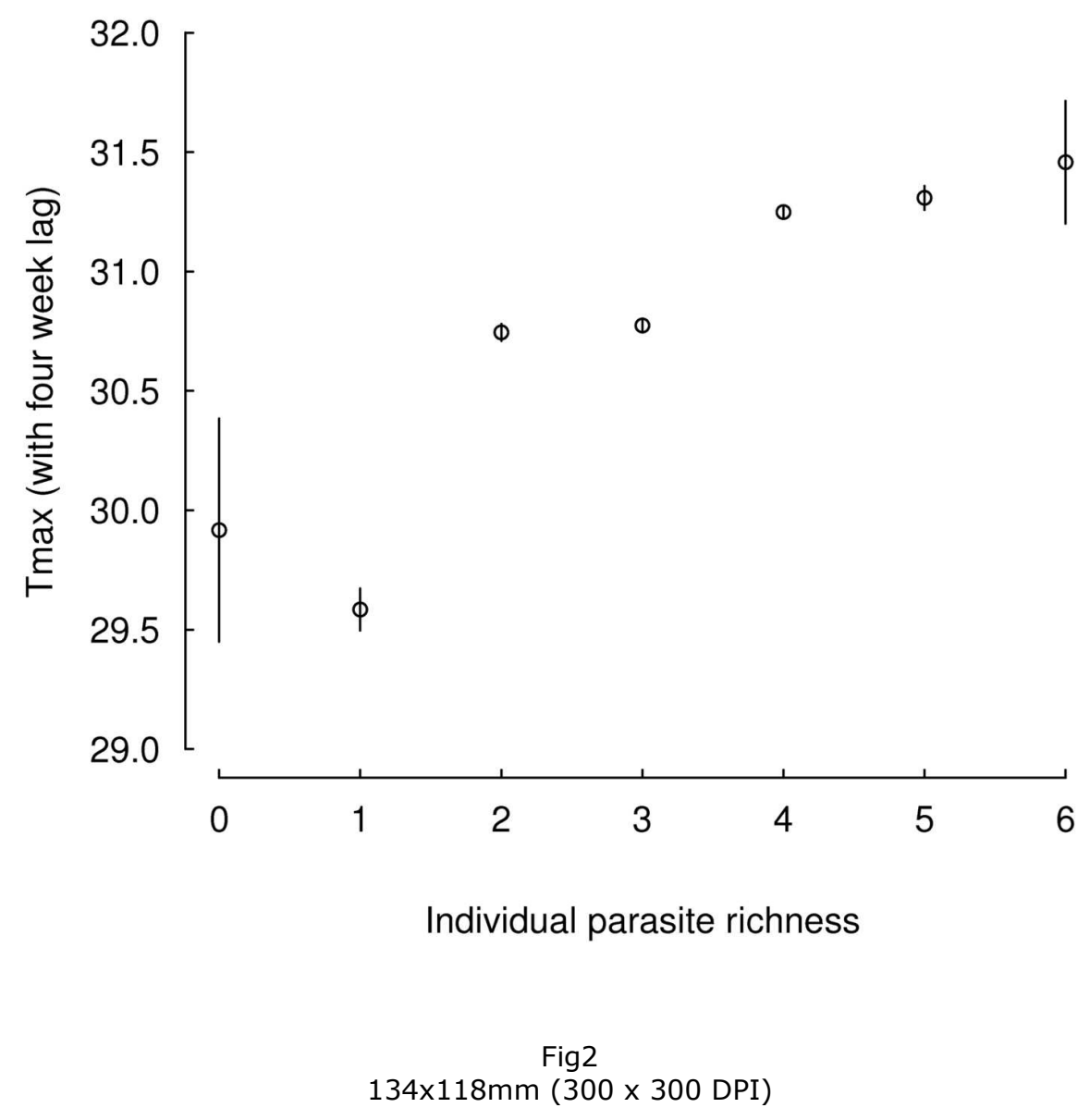

John Wiley \& Sons, Inc. 


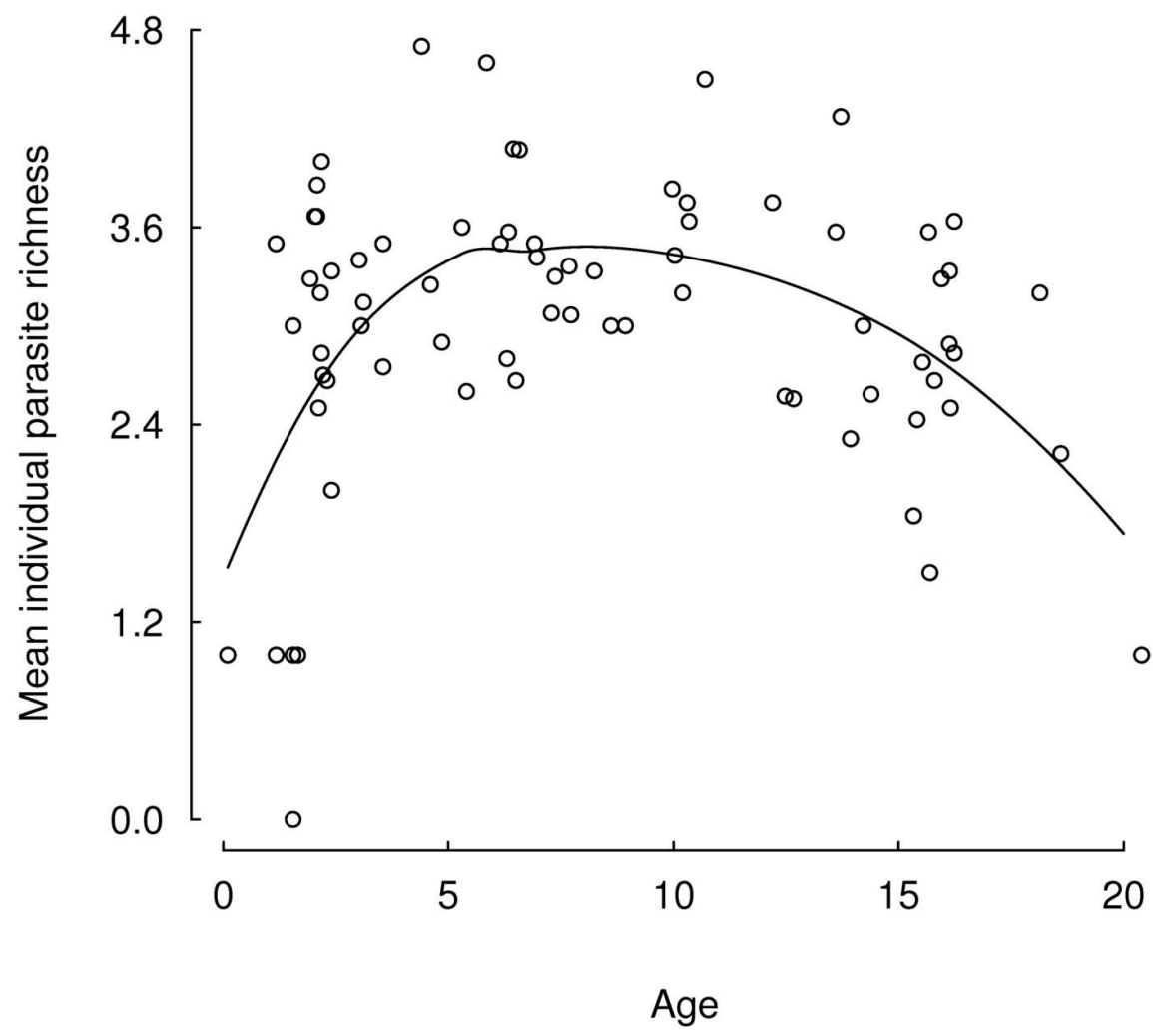

Fig3

$134 \times 118 \mathrm{~mm}(300 \times 300$ DPI $)$

John Wiley \& Sons, Inc. 


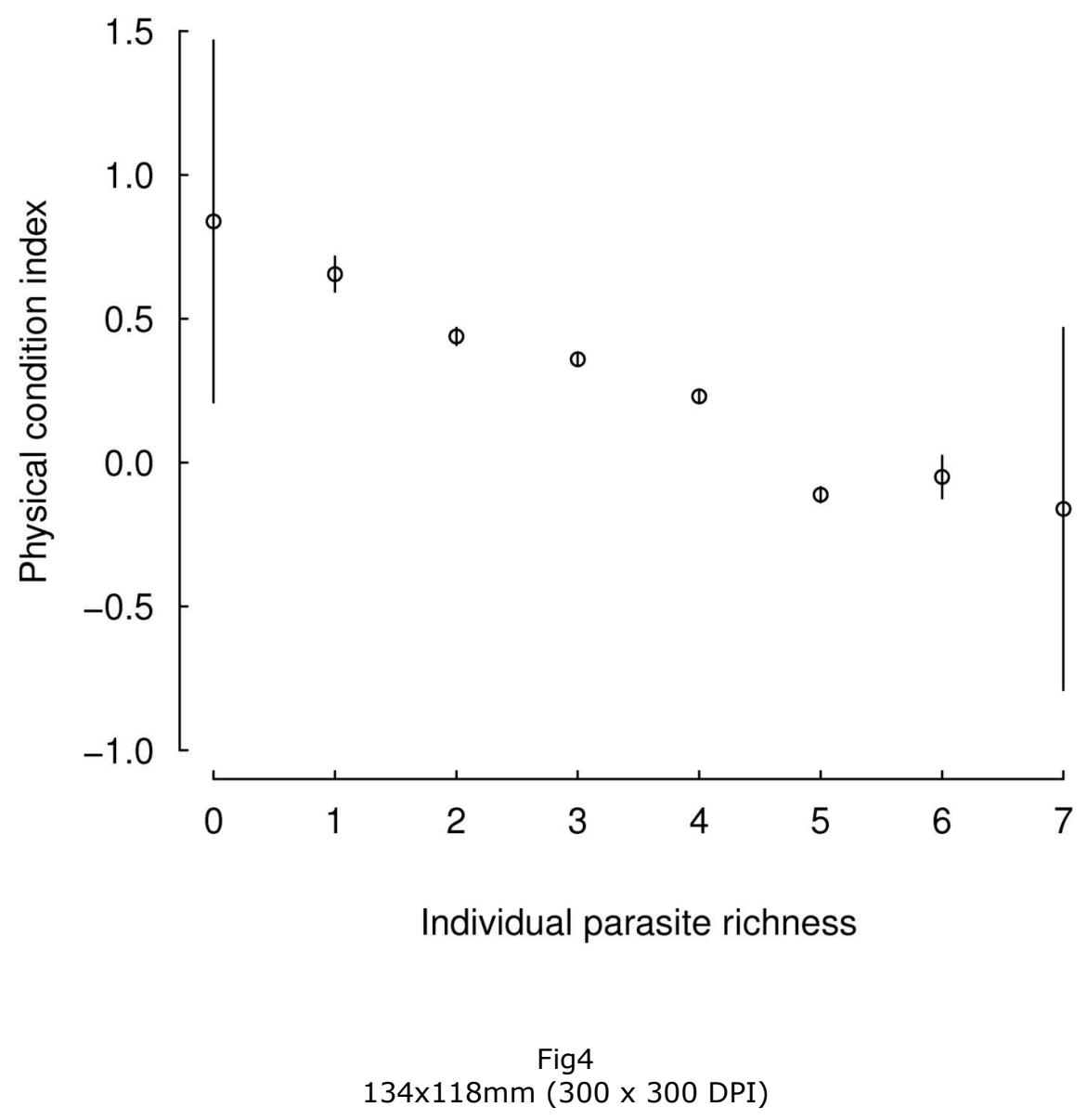

John Wiley \& Sons, Inc. 